\title{
RAUWOLFIA SERPENTINA (SERPASIL) IN PSYCHIATRY
}

\author{
BY \\ J. D. GLYNN \\ From Whittingham Hospital, nr. Preston, Lancs
}

The therapeutic problem of satisfactorily controlling acute and chronic states of psychomotor excitement is an ever-present one confronting psychiatrists engaged in hospital practice. Admittedly, the application of current methods of treatment, such as systematic pharmacological sedation by means of barbiturates and other drugs or electroconvulsive therapy, will in most cases control excited behaviour. It is a common experience, however, that even after adequate and efficient treatment a number of patients either do not respond satisfactorily to these measures or exhibit a tendency to relapse fairly rapidly. Rauwolfia serpentina (" serpasil "), a new drug, is of undoubted value in the treatment of these cases and may in time supersede the established methods, which are not altogether free from disadvantages and risks, however much minimized by skilled and efficient application.

\section{Pharmacology}

Reserpine (" serpasil ") is the chief active principle of Rauwolfia serpentina. It is a crystalline alkaloid isolated from a plant, Rauwolfia serpentina, growing mainly in India but also found in Ceylon, Burma, the Malay Peninsula, and in certain islands of that area. It is a rather small plant, growing to a height of about $3 \mathrm{ft}$., and bearing white or pinkish flowers. It has long, tapering, crooked roots, which contain most of the alkaloid.

This drug has long been used in India, principally by Ayurvedic practitioners as a remedy for snake bites and as a cure for dysentery. Latterly, it was used for insomnia, hypochondria, and insanity. Its use in Europe was known over 300 years ago, when it was stated to be of value in the treatment of anxiety states. The empirical formula of Rauwolfia serpentina is $\mathrm{C}_{33} \mathrm{H}_{40} \mathrm{O}_{9} \mathrm{~N}_{2}$, and the structural formula proved to be as shown (Siddiqui and Siddiqui, 1931; Müller, Schlittler, and Bein, 1952 ; Dorfman, Furlenmeier, Huebner, Lucas, MacPhillamy, Müller, Schlittler, Schwyzer, and St. André, 1954).

The principal action of the drug appears to be an alteration of sympathetic-parasympathetic balance by the partial suppression of sympathetic predominance at the hypothalamic level (Plummer, Barrett, Wagle, and Yonkman, 1953 ; Trapold, Plummer, and Yonkman, 1954 ; Tripod, Bein, and Meier, 1954.)

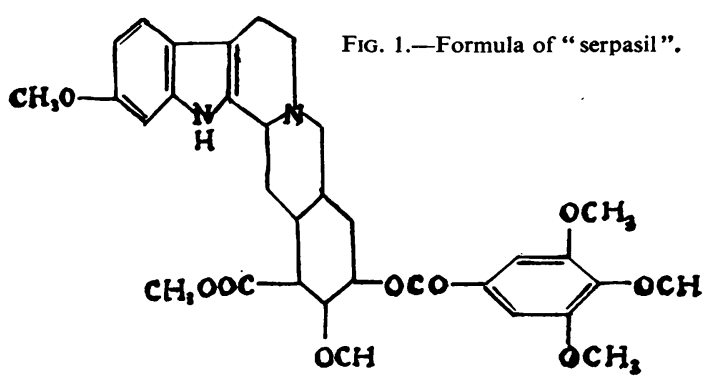

Physiological Effects

Serpasil, administered in tolerable doses, causes sedation, bradycardia, hypotension, nasal stuffiness, and gain in weight. It can be taken indefinitely and does not result in the development of tolerance or addiction. Excessive dosage is stated to cause diarrhoea, nightmares, and agitated depression (Wilkins, 1952; Wilkins and Judson, 1953; Wilkins, Judson, and Stanton, 1952 ; Wilkins, Judson, Stone, Hollander, Huckabee, and Friedman, 1954).

None of the cases reported here required treatment for diarrhoea or nasal stuffiness. Some patients complained of tiredness and drowsiness, but proved capable when stimulated of immediately mobilizing sufficient energy to overcome their sleepiness and carry out required activity. A subjective sensation of dizziness was experienced by two patients at the beginning of medication. These symptoms proved transient, disappearing in a week or ten days, and in all cases the patient remained ambulant. The only other significant side-effect occasionally complained of was heavy dreaming, sometimes erotically tinged. Blood examinations and analysis of urine 
remained normal throughout treatment and subsequently.

\section{Psychological Effects}

Perusal of the literature on Rauwolfia serpentina indicates that in the opinion of several investigators the drug produces certain definite psychological effects. Under its influence patients tend to be less susceptible to circumstances and situations formerly capable of producing symptoms such as anxiety or depression. They exhibit greater spontaneity, tend to be more sociable and optimistic, and as a result are more accessible to psychotherapy and in a better position to respond effectively. The sedative and relaxing effects of the drug appear to diminish tension and to exert a calming effect on excited, tense, hyperactive patients (Kline, 1954 ; Hakim, 1953).

\section{Dosage and Administration}

Serpasil is effective administered by either oral or parenteral routes. In cases exhibiting severe excitement parenteral injection of $5 \mathrm{mg}$. rapidly produces a calming effect. Depending on the severity of the excitement this can be repeated eight hourly, or the initial dose can be followed by oral medication, beginning with $1 \mathrm{mg}$. every four hours. Parenteral administration can usually be discontinued after one or two days, and the oral dosage may be increased to 5 to $15 \mathrm{mg}$. daily as required. No untoward side-effects were observed with these doses. Shivering and flushing of the entire body sometimes occurred 30 to 45 minutes after an intravenous or intramuscular injection of $5 \mathrm{mg}$. Occasionally a patient complained of vertigo or weakness but all remained ambulant. Administration of the drug was invariably accompanied by a drop in blood pressure and bradycardia. Correlation between the sedative effect and the effect on blood pressure and pulse rate was not established.

In less pronounced psychomotor restlessness, such as that seen in senile agitation, doses of from 0.5 mg. to $1 \mathrm{mg}$. t.i.d. are usually sufficient to produce tranquillity.

Experience gained in the use of the drug indicates that treatment can be continued indefinitely without any apparent ill-effects.

Concomitant administration of other drugs does not impair the effectiveness of "serpasil " (Kline, 1954). There is a reference in the literature to a death while a patient was receiving both digitalis and Rauwolfia serpentina (De and Chatterjee, 1941).

Hakim claimed good results in psychoses and psychoneuroses using a preparation containing Rauwolfia serpentina combined with E.C.T. (Hakim, 1953).

\section{Results}

One hundred and eighteen male patients ranging in age from 20 to 76 years treated with " serpasil" over a period of eight months have provided experience on which this report is based. The subjects for testing, with the exception of 12 cases of acute mania and two organic confusional states due to uraemia, were selected from chronic patients persistently exhibiting disturbed behaviour.

Serpasil proved to have a definite sedative action although it was not equally effective in all cases. The group of manic depressive patients in the manic or hypomanic state responded best. The tranquillizing effects of the drug became apparent within 24 hours of administration either by the parenteral or oral route, eliminating any necessity for barbiturate sedation or E.C.T. Psychomotor excitement diminished and was replaced by cooperative behaviour rendering nursing care and attention easier.

The drug given in adequate dosage appears to control satisfactorily most kinds of severe excitement commonly encountered in admission or refractory wards, e.g., catatonic schizophrenia, organic toxic confusional states as seen in uraemic conditions, post-epileptic confusional states, and senile psychoses.

Due to the beneficial influence of " serpasil" it was found practicable, in one refractory ward, to empty permanently all the side-rooms of patients who previously had occupied them for long periods.

The incidence of impulsive and noisy conduct was reduced following exhibition of the drug, an observation confirmed by the evidence of daily ward records and casualty reports.

TABLE

ANALYSIS OF RESULTS

\begin{tabular}{|c|c|c|c|c|c|}
\hline Condition & $\begin{array}{c}\text { Re- } \\
\text { covered }\end{array}$ & $\begin{array}{c}\text { Much } \\
\text { Im- } \\
\text { proved }\end{array}$ & $\underset{\text { proved }}{\text { Im- }}$ & $\begin{array}{c}\text { Un- } \\
\text { changed }\end{array}$ & Total \\
\hline $\begin{array}{l}\text { Schizophrenia } \\
\text { Acute mania } \\
\text { Chronic mania . } \\
\text { Post-leucotomy .. } \\
\text { Mental deficiency .. } \\
\text { Senile psychosis . } \\
\text { Organic toxic con- } \\
\text { fusional states } \\
\text { (uraemia) . } \\
\text { Post-epileptic con- } \\
\text { - fusional state .. }\end{array}$ & $\begin{array}{l}\overline{7} \\
\bar{Z} \\
-\end{array}$ & $\begin{array}{r}27 \\
4 \\
9 \\
1 \\
2 \\
7\end{array}$ & $\begin{array}{r}33 \\
1 \\
4 \\
2 \\
2\end{array}$ & $\frac{15}{1}$ & $\begin{array}{r}75 \\
12 \\
14 \\
1 \\
4 \\
9\end{array}$ \\
\hline Totals & 9 & 50 & 43 & 16 & 118 \\
\hline
\end{tabular}

The group " much improved" comprises those patients no longer The group "much improved" comprises those patients no longer
exhibiting excited or impulsive behaviour who have become more cooperative and generally exhibit a greater degree of social integration. It is in this group that improvement in insight frequently occurs. Delusions, if present, apparently cause little or no distress.

The "improved" group contains patients whose tendency to antisocial or excited behaviour is much diminished, who are quieter and better behaved than before treatment, and who are manageable without recourse to other therapeutic measures such as sedation or E.C.T. 
Serpasil proved valuable in averting the onset of catatonic excitement in three chronic patients exhibiting typical prodromal symptoms, which in the past inevitably heralded the onset of episodes of excited, disturbed behaviour.

Therapeutic results are summarized in the accompanying Table.

\section{Discussion}

Serpasil has many advantages as a psychiatric therapeutic agent not possessed by the standard methods of treatment in current use. Its valuable sedative action, achieved in a setting of clear consciousness and free from the inhibiting effects commonly associated with the barbiturates, or the disorganizing effect on the higher brain functions of E.C.T., is of the utmost value in establishing rapport with patients. By means of its relaxing and calming action, anxiety and tension are diminished. Patients under its influence exhibit greater spontaneity, tend to be more sociable and optimistic and as a result are more accessible to psychotherapy and in a better condition to respond effectively.

Following treatment with "serpasil", hyperactive, aggressive, and resistive patients tend to become quiet and cooperative. Nursing care and necessary tasks, such as feeding, dressing, and bathing, are no longer so arduous and depressing. Arising from improvement in behaviour, the need for measures such as barbiturate sedation or repeated courses of E.C.T. is lessened.

The administration of "serpasil" is relatively simple and side-effects are of minor significance. The use of the drug may be continued for long periods with little or no risk and only minimum supervision is required.
The drug proved a useful addition to therapeutic resources in cases reported here. Further research, however, is needed to establish more precisely the psychiatric conditions in which it is likely to be most beneficial and to investigate the possible modes of action.

\section{Summary}

Rauwolfia serpentina (" serpasil") is an effective sedative for use in mental hospitals, although it is not equally effective in all cases. It reduces anxiety and drive and exerts a calming effect on psychomotor excitement. Patients under its influence are more accessible to psychotherapy.

Acknowledgment is due to Ciba Laboratories Ltd. for furnishing "serpasil"; Dr. A. R. Grant, Medical Superintendent, for permission to publish; and the nursing staff, Whittingham Hospital, for their cooperation.

\section{REFERENCES}

De, M. N., and Chatterjee, T. (1941). Indian med. Gaz., 76, 724.

Dorfman, L., Furlenmeier, A., Huebner, C. F., Lucas, R., MacPhillamy, H. B., Müller, J. M., Schlittler, E., Schwyzer, R., and St. André, A. F. (1954), Helv chim Acta, 37, 59.

Hakim, R. A. (1953). Indigenous Drugs in the Treatment of Mental Disease. Sixth Gujrat and Saurashtra Provincial Medical Conference. Baroda, India.

Kline, N. S. (1954). Ann. N.Y. Acad. Sci., 59, 123 and 126.

Müller, J. M., Schlittler, E., and Bein, H. J. (1952). Experientia, Basel, 8, 338.

Plummer, A. J., Barrett, W. E., Wagle, G., and Yonkman, F. F. (1953). Fed. Proc., 12, 357 .

Siddiqui, S., and Siddiqui, R. H. (1931). J. Indian chem. Soc., 8, 667.

Trapold, J. H., Plummer, A. J., and Yonkman, F. F. (1954). J. Pharmacol., 110, 205.

Tripod, J., Bein, H. J., and Meier, R. (1954). Arch. int. Pharmacodyn., 96, 406.

Wilkins, R. W. (1952). Ann. intern. Med., 37, 1144.

, and Judson, W. E. (1953). New Engl. J. Med., 248, 48

- - , and Stanton, J. R. (1952). Proc. New Engl. Cardiovas. Soc. (1951-52), p. 34. - $\begin{aligned} & \text { Friedman, I. H. (1954). New Engl. J. Med., 250, 477. } \\ & \text { Stone, R. And }\end{aligned}$

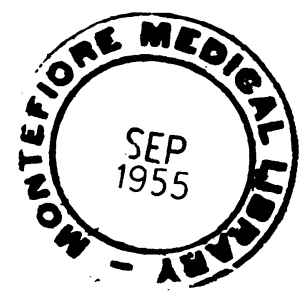

